\title{
Doğrusal Olmayan Birim Kök Testleriyle Rusya için Satın Alma Gücü Paritesi Hipotezinin İncelenmesi
}

\author{
Revisiting Purchasing Power Parity Hypothesis for Russia Using Nonlinear \\ Unit Root Tests
}

\section{Doç. Dr. Seymur Ağazade}

\section{Öz}

Bu çalışmada Rusya için Satın Alma Gücü Paritesi (PPP) yaklaşımının geçerliliği Kasım 1993 - Nisan 2013 dönemine ait veri seti kullanılarak araştırılmıştır. Bu amaçla asimetrik intibaka izin veren ve vermeyen doğrusal olmayan birim kök testleri yardımıyla rubleye ait reel efektif döviz kuru serisinin durağanlık özellikleri incelenmiştir. Doğrusal dişıllğın yanı sıra reel döviz kurunun asimetrik intibakına da izin veren yöntemler ruble reel efektif kurunun durağan olduğuna ilişkin bulgular sunmakta ve Rusya için PPP yaklaşımının geçerliliğini desteklemektedir.

Anahtar Kelimeler: Satın Alma Gücü Paritesi Hipotezi, Reel Efektif Döviz Kuru, Doğrusal Dişılık, Rusya

\begin{abstract}
The article examines the validity of Purchasing Power Parity (PPP) hypothesis for Russia by using the data set belonging to the period November 1993 to April 2013. Two groups of nonlinear unit root tests are used to investigate the stationarity characteristics of real effective exchange rate series of Russian ruble. While the first group of the tests models structural change as a smooth monotonic transition, second group takes into account both structural change and asymmetric adjustment characteristics of real exchange rate. Findings of unit root tests that allow for asymmetric adjustment support the stationarity of real effective exchange rate series and provide evidences on the validity of PPP hypothesis for Russia.
\end{abstract}

Keywords: Purchasing Power Parity Hypothesis, Real Effective Exchange Rate, Nonlinearity, Russia

\section{Giriş}

Satın alma gücü paritesi (PPP) mutlak yaklaşımı aynı para birimi ile ifade edildiğinde yurtiçi ve yurtdışı fiyatların eşitleneceğini ima eder. İşlem maliyetleri, dış ticaret kısıtlamaları, tekelleşme, ticarete konu olmayan malların varlığı, başlangıç yatırım sermayesinin büyüklügü, ülkelerin fiyat endeksi sepetlerine dahil olan malların veya bunların ağırlıklarının farklı olması, fiyat ve döviz kuru müdahaleleri gibi birçok neden PPP mutlak yaklaşımının gerçekleşmemesine neden olabilir. PPP nispi yaklaşımı ise yurtiçi ve yurtdışı fiyatların eşitleneceğini değil, beraber hareket edeceğini öngörür. Bu bağlamda, ulusal malların yabancı mallar cinsinden karşılığını ifade eden reel döviz kurunun uzun dönem denge düzeyinden sapmalarının kalıcı veya geçici özellikler taşıması PPP nispi yaklaşımının geçerliliği bakımından önemlidir. Reel döviz kurunun uzun dönem denge düzeyine tekrar intibak etmesi sapmaların geçici ve dolayısıyla PPP hipotezinin geçerli olması anlamına gelir. Reel döviz kurunun uzun dönem denge düzeyinden kalıcı şekilde uzaklaşması ise sapmaların kalıcı olduğunda gerçekleşir.

Bu çalışmada, sınırlı sayıda çalışmanın bulunduğu Rusya için PPP hipotezinin geçerli olup olmadığ Kasım 1993 - Nisan 2013 dönemine ait veri seti kullanılarak araştırılmıştır. Bu amaçla ruble reel efektif döviz kuru (RER) serisinin durağanlık özellikleri doğrusal olmayan birim kök testleriyle incelenmiştir. Uygulanan doğrusal olmayan birim kök yaklaşımlardan ilk üçü yapısal değişmeyi yumuşak geçiş şeklinde modelleyen Kapetanios, Shin ve Snell (2003, KSS), Kruse (2010) ve Leybourne, Newbold ve Vougas (1998, LNV) tarafından önerilen yaklaşımlardır. Bu çalışmada uygulanan diğer doğrusal olmayan birim

Doç. Dr. Seymur Ağazade, Recep Tayyip Erdoğan Üniversitesi İİBF İktisat Bölümü, seymur.agazade@erdogan.edu.tr 
kök testleri ise yapısal değişmenin yanı sıra asimetrik intibaka da izin veren Sollis (2004) ve Cuestas ve Ordóñez (2012) yöntemleridir. Asimetrik intibaka izin veren test sonuçları Rusya için PPP geçerliliğini desteklemektedir.

Çalışmanın devamı şu şekilde düzenlenmiştir. Takip eden bölümde merkezi planlamaya dayalı sistemin çöküşünden sonra Rusyảda yaşanan ekonomik gek lişmelere ilişkin öz bilgi verilmiş, döviz kurunun ve fiyatlar genel düzeyinin seyri izlenmiştir. Ardından Rusya'da PPP hipotezinin geçerliliğine ilişkin yapılan diğer çalışmalar değerlendirilmiştir. Dördüncü bölümde durağanlık incelemesinde uygulanan birim kök testleri tanıtılmıştır. Beşinci bölümde test bulguları sunulmuştur. Sonuncu bölümde ise bulgular doğrultusunda değerlendirmelerde bulunulmuştur.

\section{Sovyet Sonrası Dönemde Rusya'da Bazı Temel Ekonomik Gelişmeler}

Sovyetler birliğinin ardından 1990'ların ilk yıllarında Rusya ve diğer eski birlik üyeleri arasında Rus rublesine dayalı bir parasal birlik sürdürülmeye çalışılmıştır. Bu parasal birlikte paranın sadece Rusya merkez bankasınca basılmasına karşın ruble bölgesindeki diğer ülkelerin merkez bankaları para politikalarını bağımsız şekilde yürütme yetkisine sahip olmuşlar. Hatta Beyaz Rusya, Moldova ve Gürcistan rubleye paralel olarak ikinci bir para kullanmışlardır. Para arzının kontrol edilemezliğini ve bu şekilde bir parasal birliğin uygulanabilirliğinin olmadığını gören Rusya merkez bankasi Temmuz 1993'de yeni ruble basımını gerçekleştirmiş ve eski rublenin Rusya s1nırları içinde kullanımını durdurmuştur. Bunun yanı sira Rusya parasal birlikteki diğer ülkelerden ruble bölgesini terk etmelerini veya merkez bankalarının yetkilerini Rusya merkez bankasına devretmelerini istemiştir. Bu süreçten önce Letonya, Litvanya, Estonë ya, Ukrayna ve Kırgızistan parasal birliği terk etmiş̣ lerdi. Rusyảnın almış olduğu bu önlemin ardından Azerbaycan ve Gürcistan, 199r yılı sonlarına doğru ise Ermenistan, Beyaz Rusya, Kazakistan, Moldova, Türkmenistan ve Özbekistan ruble bölgesini terk etti. Birlikte kalan son ülke olan Tacikistan da 1995'te ulusal parasını tedavüle bıraktı ve parasal birlikten çıktı.

Sovyetler Birliğinin siyasi çöküşü tüm diğer geçiş ekonomileri gibi Rusya ekonomisi üzerinde de ağır sonuçlar doğurmuştur. Bunun yanı sıra geçiş dönemi başlangıç yıllarında uygulanan parasal birlik Rus mallarının birlik dahilindeki diğer ülkelere karşılıksız transferine neden olmuştur. Şöyle ki, Rusya'dan ithal edilen malların karşılıkları yine Rusya merkez bankasından alınan karşılıksız kredilerle ödenmiştir. Ayrıca diğer merkez bankalarının para politikalarını yürütmede bağımsız olmaları ve bazılarının paralel ikinci bir para tedavüle bırakmaları Rusya merkez bankası için para arzının kontrol edemezliğine neden olmuştur.

Tablo 1'de Rusyảnın merkezi planlama sonrası dönemine ilişkin büyüme ve enflasyon oranları, dolar kuk runda yıllık yüzde değişim ve RER değerleri verilmiştir. Tablodan da görüldüğ̈̈ gibi 1990-1996 yıllarında Rusya ekonomisi sürekli olarak 7 yll boyunca kümülatif olarak yaklaşı \%41.91 oranında küçülmüş, 1996 yılı reel GSYİH'sı 1989 yılına ait değerinin ancak \%58.09'una eşit olmuştur. Fiyatlar üzerindeki kontrolün kaldırılmasıyla 1992 yılında fiyatlar genel düzeyindeki artı̧s hiperenflasyon düzeyinde gerçekleşmiştir. Tüketici fiyatları endeksinde yüzde değişim 1993-1996 yıllarında sırasıyla \%874.62, $307.63,197.47$ ve 47.74 oranındadır.

Rusya merkez bankası 8 Haziran 1992 tarihinden itibaren ruble dolar resmi kurunu haftallk temelde belirlemeğe başlamıştır. Bu dönemde resmi kurun yanı sıra Moskova Bankalararası Döviz Piyasası işlemlerie ne göre belirlenen bir piyasa döviz kuru mevcuttur (CBR, 2013). 1993 ve 1994 yllarında rublenin dolar karşısındaki değer kaybı yılsonları itibariyle sırasıyla \%235.31 ve 176.20 olmuştur. Temmuz 1995'de Rusya merkez bankası dolar kuru dalgalanmasının 4.300 ile 4.900 ruble aralığı ile sınırlı tutulacağını açıklamıştır. Banka Ocak 1996, Temmuz 1996, Ocak 1997 ve Ocak 1998'de dolar kuru için aralık bandını önceden ilan ederek yukarı yönde revize etmiştir. 1 Ocak 1998 itibariyle dolar kuru için aralık 5.750-6.350 rubledir (CBR, 2013). 1995-1997 yıllarında rublenin dolar karşısında değer kaybı sırasıyla \%35.91, 20.11 ve 7.24 oranındadır. 1998 yılına kadar RER de önceki yıllara göre sürekli artmıştır.

Geçiş dönemi durgunluğu şeklinde de ifade edilen uzun yıllar devam eden sürekli küçülmeden sonra Rusya 1997 yılında \%1.4 büyümüştür. Aynı yılda enflasyon ve ulusal paranın değer kaybı da makul düzeylerde olmuştur. Ruble dolara karş1 \%7.24 nod minal değer kaybetmesine karşın reel olarak değer kazanmıştır. Fakat Ekim 1997'de Uzak Doğu ülkelerinde baş gösteren finansal kriz Rusya’dan da ser- 
maye çıkışına ve döviz kuru üzerinde yukarı yönlü baskıya neden olmuştur. Merkez bankası 11 Kasım'da faiz oranını ve yabancı paralar için zorunlu karşılıkları artırmıştır. Ayrıca banka daha önce bir yıl için açıkladığı dolar kuru bandını döviz kuru istikrarını ve tahmin edilebilirliğini sağlamak amacıyla 1 Ocak 1998 'den itibaren geçerli olmak üzere orta vadeli (1998-2000 yılları için) döviz kuru hedefi şeklinde açıklamıştır. $\mathrm{Bu}$ hedef $1 \$=6.2 \pm \% 10$ ruble olmuştur (CBR, 2013). Rusya merkez bankasının döviz kuru istikrarına yönelik tedbirlerine karşın süreklilik arz eden bütçe açıklarının 1996-1998 yıllarında da azaltılamaması (Bütçe açığı GDP oranı bu yıllarda sırasıyla \%8.90, 8.00 ve 8.00 düzeyindedir, EBRD) Rusyảnın diş borç stokunun ve borç servisinin artmasına neden olmuştur. 1997-1999 yılları için dış borç stoku GDP oranı sirasiyla \%38.40, 70.20 ve 95.80 'dir (EBRD). Bunun yanı sıra ruble reel kurunun artması ve Rusya ihraç ürünlerinin fiyatlarının azalmasıyla dış ticaret hadlerinin Rusya aleyhine bozulması cari hesap dengesini olumsuz yönde etkilemiştir. 1997 ve 1998 yilla- rında cari hesap dengesi GDP oranı sırasıyla -\%0.02 ve 0.08 şeklinde gerçekleşmiştir (IMF, 2013). 1998 yılında Rusya merkez bankasının gösterge faizini artırması ve IMF'nin doğrudan para yardımı sermaye çıkışını engelleyememiştir. Rusya merkez bankası döviz kuru bandının artık sürdürülemez olduğunu görerek 17 Ağustos tarihinde kuru yeni bant içinde (1\$=6-9.5Ruble) dalgalanmaya bıraktığını açıklamıştır (CBR, 2013). 9.5 ruble olarak belirlenen dolar kuru üst sınırını sağlamak için Rusya merkez bankası 17 Ağustostan sonra da sürekli döviz satışı gerçekleştirmiştir ve 2 Eylülde dolar kuru için üst limit uygulamasını da kaldırmıştır (CBR, 2013). Böylelikle Eylül ayında ruble dolar karşısında \%50'nin üzerinde değer kaybetmiştir. 1998 yılı dikkate alındığında ise rublenin değer kaybı \%252.21'dir. Tablo 1'de görüldüğü gibi ruble dolara karşın 1999 yllında ise \%28.72 değer kaybetmiştir. Fakat bu değer düşüşü özellikle yılın ilk aylarındadır. Aynı şekilde RER de 1998 ve 1999 yıllarında azalmıştır.

Tablo 1. Büyüme, Enflasyon, Kur Artı̧̧ı ve RER

\begin{tabular}{|c|c|c|c|c|}
\hline Y11 & GDP büyüme (\%) & $\begin{array}{c}\text { Tüketici fiyatlarıyla } \\
\text { enflasyon (\%) }\end{array}$ & $\begin{array}{c}\text { Dolar kurunda } \\
\text { değişim (\%) }\end{array}$ & RER (2005=100) \\
\hline 1990 & -3.00 & & & \\
\hline 1991 & -5.05 & $161.0^{*}$ & & \\
\hline 1992 & -14.53 & $2506.10^{*}$ & & \\
\hline 1993 & -8.67 & 874.62 & 235.31 & 176.20 \\
\hline 1994 & -12.57 & 307.63 & 35.91 & 75.92 \\
\hline 1995 & -4.14 & 197.47 & 20.11 & 93.32 \\
\hline 1996 & -3.60 & 47.74 & 7.24 & 99.64 \\
\hline 1997 & 1.40 & 14.77 & 252.21 & 87.90 \\
\hline 1998 & -5.30 & 27.67 & 28.72 & 60.38 \\
\hline 1999 & 6.40 & 85.74 & 4.10 & 66.66 \\
\hline 2000 & 10.00 & 20.78 & 7.62 & 79.87 \\
\hline 2001 & 5.09 & 21.46 & 5.49 & 82.25 \\
\hline 2002 & 4.74 & 15.79 & -7.67 & 91.33 \\
\hline 2003 & 7.30 & 13.68 & -5.14 & 100.00 \\
\hline 2004 & 7.18 & 10.86 & 3.22 & 109.87 \\
\hline 2005 & 6.38 & 12.68 & -8.70 & 115.87 \\
\hline 2006 & 8.15 & 9.68 & -6.49 & 123.74 \\
\hline 2007 & 8.54 & 9.01 & 14.91 & 115.21 \\
\hline 2008 & 5.25 & 14.11 & 6.39 & 125.92 \\
\hline 2009 & -7.82 & 11.65 & 2.48 & 131.99 \\
\hline 2010 & 4.50 & 6.86 & 2.43 & 133.94 \\
\hline 2011 & 4.29 & 8.44 & -2.68 & \\
\hline 2012 & 3.44 & 5.07 & & \\
\hline
\end{tabular}

Kaynak: Dünya Bankası World Development Indicators ve Global Economic Monitor veri tabanı.

Not: Kur artışı dolar kurunun Aralık değerlerine göre hesaplanmıştır. * simgeli değerler EBRD’den alınmıştır. 
1997 yllı için pozitif büyümeden sonra Rusya reel GDP'si 1998 yllında tekrar \%5.30 oranında küçülmüştür. 2000 ve sonrası yıllarda ise küresel finansal krizin yaşandığ 2009 yılına kadar Rusya ekonomisi sürekli büyümüştür. Bu yıllarda Rusya ihracatının artması ve diş ticaret hadlerinin ülke lehinde değişmesi GDP büyümesinde etkili olmuştur. Aynı dönem için enflasyon rakamlarına bakıldığında ise fiyat artışlarının kontrol altına alındığı ve enflasyonun düşme eğilimi gösterdiği görülür. Tablo l'den de görüldüğü gibi 1999 yllında \%85.74'lük düzeyle Rusya krizinin de etkilerini yansitan tüketici fiyatlarıla enflasyon son yillarda \%10'un altında seyretmiştir. Enflasyonun kontrol altına alınmasında mali disiplinin sağlanmas1 etkili olmuştur. 1999 sonrası yıllarda 2009 yılına kadar Rusya federal hükümet bütçesi sürekli olarak fazla vermiştir. 1999 yılında \%90'ın üzerine çıkan dış borç stoku GDP oranı sonraki yıllarda sürekli olarak azalmıştır. 1999 öncesi yıllarda düşük düzeyde fazla veya açık veren cari hesap dengesi bu yıldan itibaren yüksek düzeyde ve sürekli olarak fazla vermiştir. Örneğin 1999, 2000 ve 2001 yillarında sırasıyla \%12.57, 18.04 ve 11.07 olan cari hesap dengesi GDP oranı 2009 sonrası yıllarda $\% 5$ 'in altına inse de diğer yıllarda da \%5'in üzerinde seyretmiştir (IMF, 2013). Bütün bunlar belirtilen dönemin bazı yıllarında rublenin dolar karşısında değer kazanmasına efektif kurun ise sürekli artmasına neden olmuştur.

1998 sonrası dönemde Rusya merkez bankası kura herhangi doğrudan bir müdahalede bulunmamıştır. Ağırlıklı olarak ihracat gelirlerinin ruble değeri üzerinde oluşturduğu yukarı yönlü baskı kontrol edilmeğe çalışılmış ve rublenin değer aşırı döviz alımlarıyla hafifletilmeye çalışlmıştır. Buna rağmen 2008 Ağustosuna kadar dolar kuru sürekli düşmüştür. 2008 küresel finansal krizin Rusyada etkisini gösterdiği dönemde sermaye çıkışı rublenin önemli düzeyde değer kaybetmesine neden olmuştur. Sermaye çıkışının yanı sıra dünya enerji fiyatlarının da önemli derecede azalması bunda etkili olmuştur. Şöyle ki 2008 yılında 1.76 olan Rusya dış ticaret hadleri 2009 yilında 1.24 düzeyine inmiştir (WB, 2013). 1999 sonrasında sürekli büyüyen Rusya ekonomisi 10 ylllık bir aradan sonra 2009 yılında \%7.82'lik negatif büyüme göstermiştir. Sermaye çıkışı ve ihraç gelirlerinin azalması nedeniyle Temmuz 2008'de 23.36 olan ruble dolar kuru Şubat 2009'a kadar \%53.30 oranında değer kaybederek 35.81 olmuştur. 2009 yılı sonuna kadar ise dolar kuru 30 ruble düzeyine dönmüş ve sonraki dönemde 27.91 ile 32.82 aralığında seyretmiştir (WB, 2013).

\section{Literatür}

Tablo 2'de PPP hipotezinin Rusya için geçerli olup olmadığının araştırıldığ 1 çalışmalar araştırma döa nemleri, reel kur hesaplamasında dikkate alınan yabancı ülke, kullanılan yöntem ve elde edilen sonuçlar bakımından özetlenerek verilmiştir. Dikkate alınan yabancı ülke bakımından çalışmalar incelendiğinde Nusair (2013), Bahmani-Oskooee, Kutan ve Zhou'un (2008 ve 2009) RER'i kullandıkları, Baharumshah ve Borsic'in (2008) rublenin hem dolar hem de Euro reel kurlarını kullandıkları görülmektedir. Diğer çalışmalardaki yabancı ülke ise ABD'dir.

Choudhry (1999), Solakoglu (2006), Baharumshah ve Borsic, (2008), Sideris (2006), Bahmani-Oskooee, Kutan ve Zhou (2009) ve Yotopoulos ve Sawada (2006) çalışmalarında doğrusal yöntemler kullanılırken, diğer çalışmalarda ise doğrusal dışı yöntemlere veya her iki yönteme başvurulduğu görülmektedir. Sideris (2006), Bahmani-Oskooee, Kutan ve Zhou (2008) ve Liu, Zhang ve Chang (2012) PPP hipotezinin Rusya'da geçerli olmadığı sonucuna ulaşmışlar. Bahmani-Oskooee, Kutan ve Zhou (2009), Choudhry (1999), Solakoglu (2006), Baharumshah ve Borsic (2008), Sideris (2006) ve Yotopoulos ve Sawada’na (2006) ait doğrusal veya panel veri sonuçları PPP geçerliliğini destekleyici bulgular sunmaktadır. Fakat Telatar ve Hasanov (2009) ve Nusair (2013) ise doğrusal dişılığın yanı sıra asimetrik intibaka izin veren yöntemlerde aynı sonuca ulaşabilmişler. Asimetrik düzeltmeye izin veren koentegrasyon yöntemlerini kullanan Chang ve Liu (2010), Chang, Su, Zhu ve Liu (2010) ve Chang ve Tzenge (2011) ait bulgular da Rusya için PPP'nin geçerli olduğunu desteklemektedir.

\section{Yöntem}

Rusya için PPP hipotezi geçerliliğinin incelendiği bu çalışma RER serisinin durağanlık özelliklerinin asimetrik intibakı dikkate almayan ve alan doğrusal olmayan birim kök testleriyle test edilmesine dayanmaktadır. Uygulanan doğrusal olmayan birim kök testlerinden ilk üç asimetrik intibakı dikkate almayan testlerdir. Bunlar Kapetanios, Shin ve Snell (2003, KSS), Kruse (2010) ve Leybourne, Newbold ve Vougas (1998, LNV) testleridir. Doğrusal dışıllğıın yanında asimetrik intibaka da izin veren birim kök testleri Sollis (2004) ve Cuestas ve Ordóñez (2012) testleridir. Ayrıca çalışmada karşılaştırma için doğrusal genelleştirilmiş Dickey ve Fuller (1979, ADF) testi de uygulanmıştır. İlgili literatürde yaygın şekilde kullanıl- 


\begin{tabular}{|c|c|c|c|c|c|c|c|c|c|c|c|}
\hline & 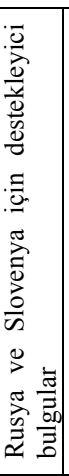 & 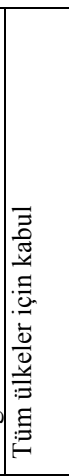 & 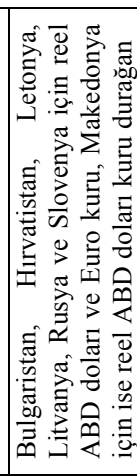 & 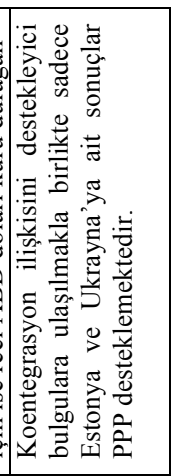 & 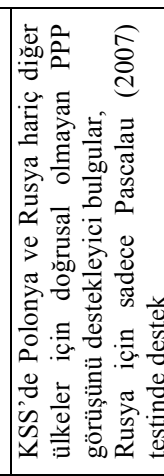 & 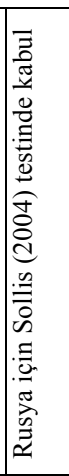 & 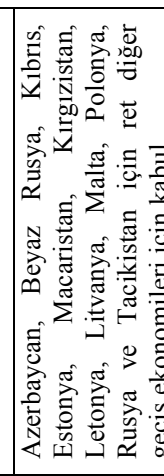 & 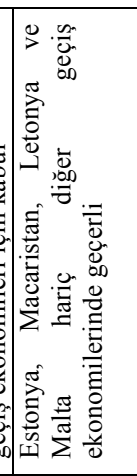 & 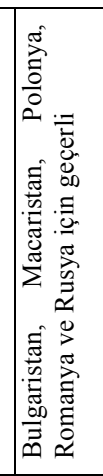 & 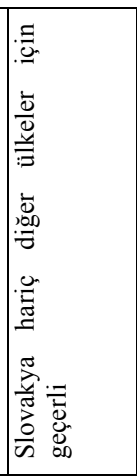 & 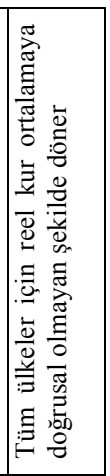 \\
\hline & 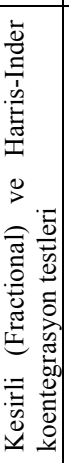 & 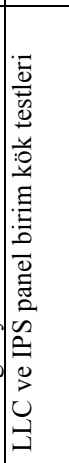 & 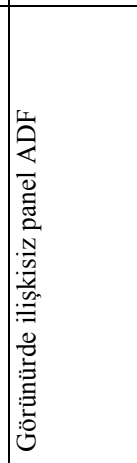 & 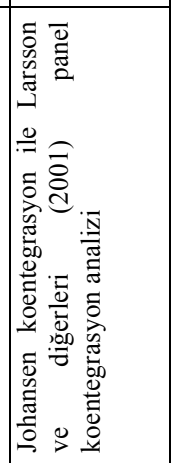 & 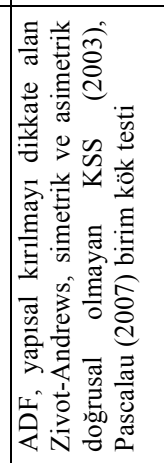 & 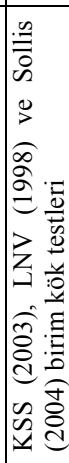 & 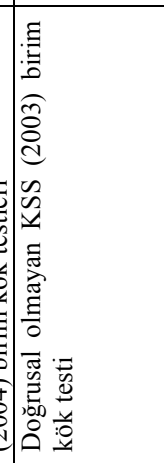 & 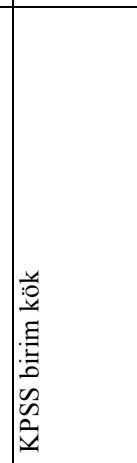 & 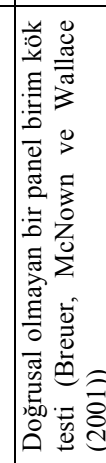 & 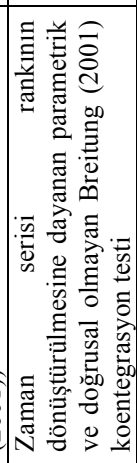 & 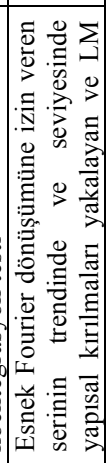 \\
\hline & & 离 & 章。 & 鲜 & 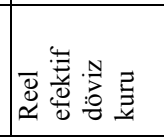 & 离 & 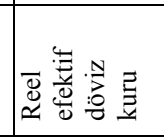 & 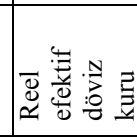 & 命 $\frac{\bar{t}}{0}$ & 㠃壱 & 爰 \\
\hline & 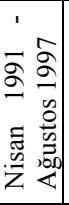 & ڤิे & 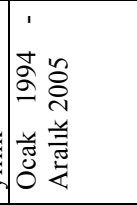 & 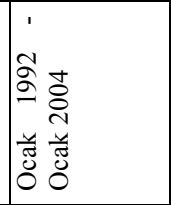 & 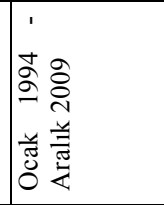 & 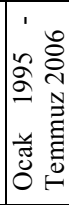 & 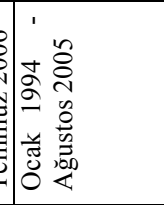 & 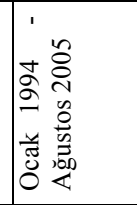 & 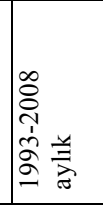 & 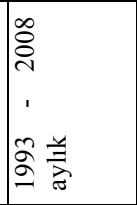 & $\begin{array}{l}\sqrt{2} \\
1 \\
2 \\
2 \\
2\end{array}$ \\
\hline & 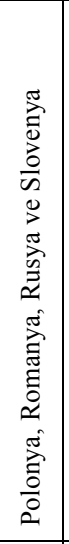 & 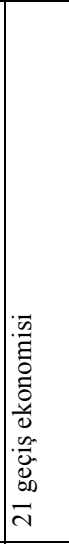 & 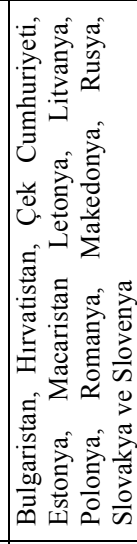 & 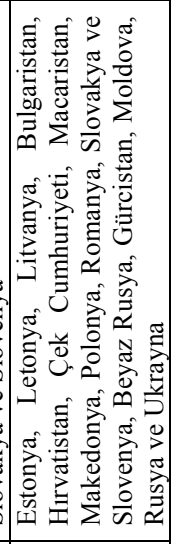 & 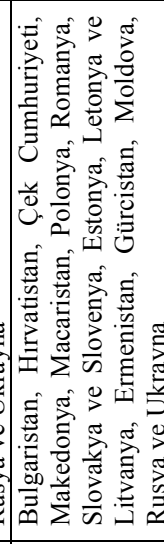 & 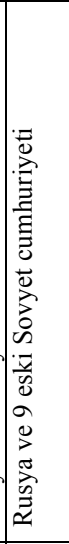 & 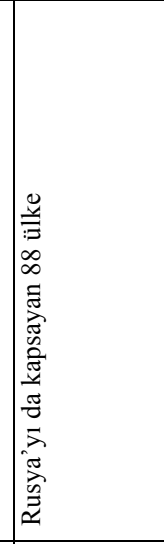 & 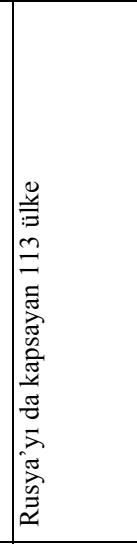 & 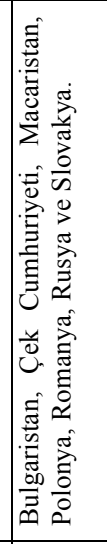 & 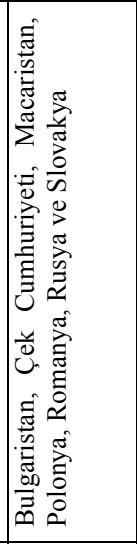 & 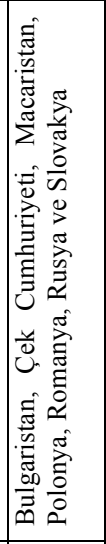 \\
\hline & 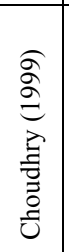 & 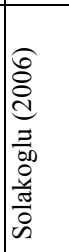 & 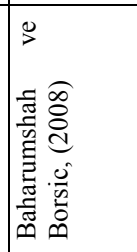 & 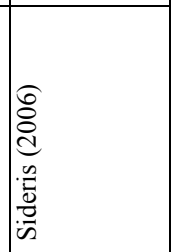 & 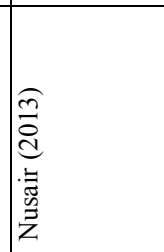 & 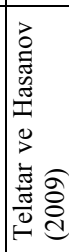 & 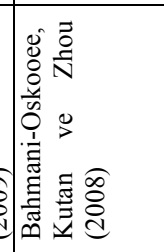 & 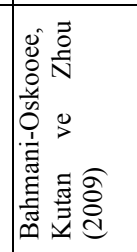 & 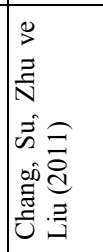 & 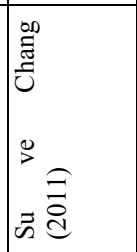 & 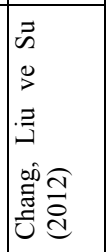 \\
\hline
\end{tabular}




\begin{tabular}{|c|c|c|c|c|c|c|c|}
\hline 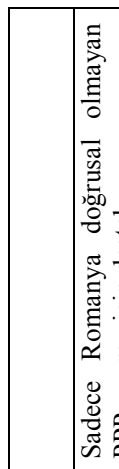 & 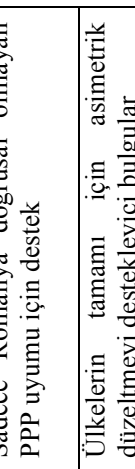 & 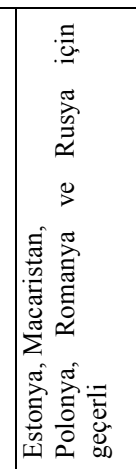 & 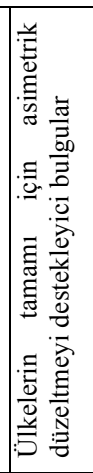 & 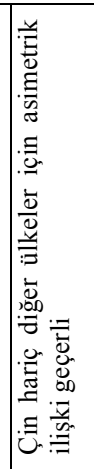 & 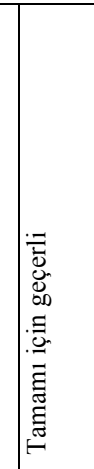 & 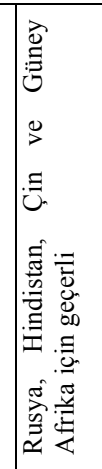 & 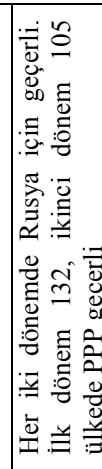 \\
\hline 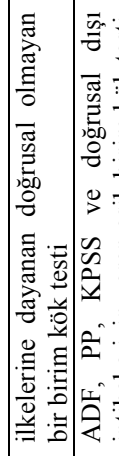 & 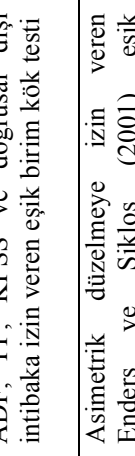 & 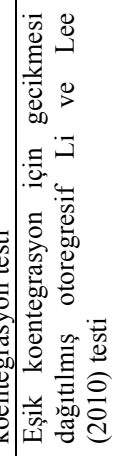 & 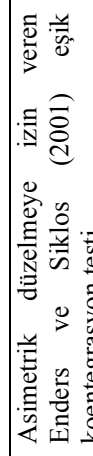 & 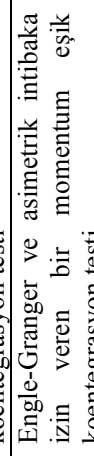 & 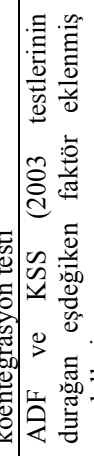 & 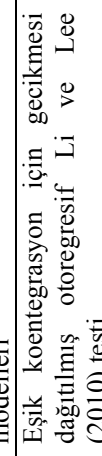 & 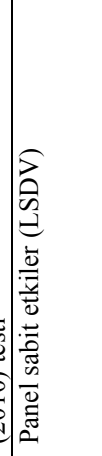 \\
\hline & 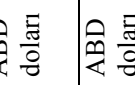 & 产 & 商壾 & 商㡲 & 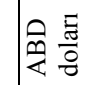 & 商㞗 & 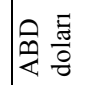 \\
\hline & 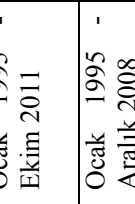 & 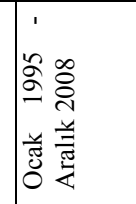 & 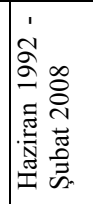 & 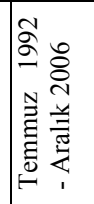 & 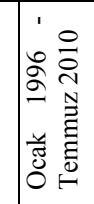 & 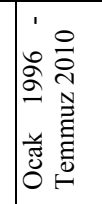 & 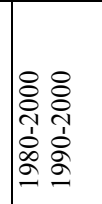 \\
\hline & 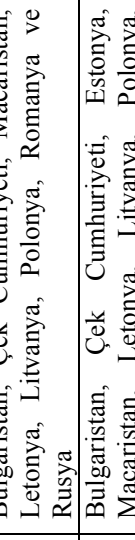 & 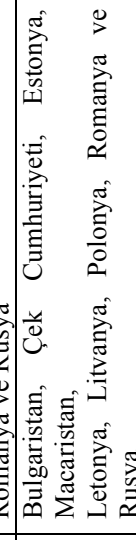 & 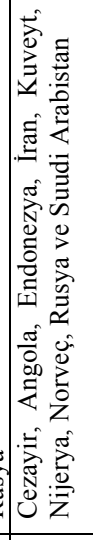 & 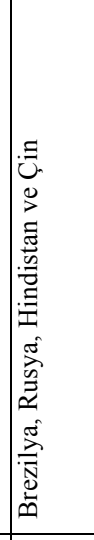 & 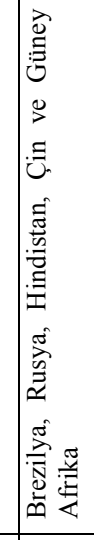 & 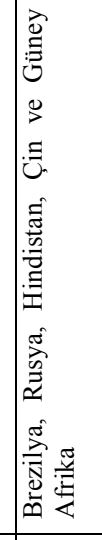 & $\begin{array}{l}\text { 音 } \\
\cong \\
\Omega\end{array}$ \\
\hline & 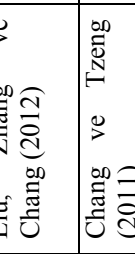 & 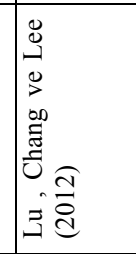 & 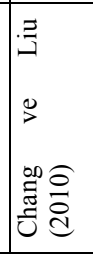 & 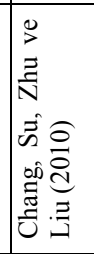 & 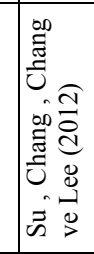 & 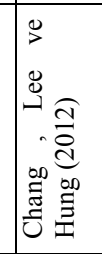 & 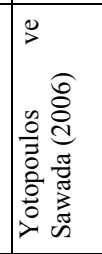 \\
\hline
\end{tabular}


dığından ADF birim kök testine ilişkin metodik açıklama burada verilmemiştir. Yapısal değişmenin üstel yumuşak geçiş şeklinde modellendiği KSS testinde durağan değildir şeklinde ifade edilen boș hipotez küresel olarak durağan (globally stationary) üstel yumuşak geçişli otoregresif süreçlere karşı test edilir. KSS geçiş değişkeni gecikmesinin bire eşit olduğunu varsayarak yumuşak geçişli otoregresif temel modelin birinci mere tebeden Taylor yaklaşıklığını elde etmektedir:

$$
\Delta y_{t}=\sum_{j=1}^{p} \rho \Delta y_{t-j}+\delta y_{t-1}^{3}+e_{t}
$$

Burada doğrusal dışı durağanlık parametresine ilişkin t-istatistiği ile sinanır.

Kruse (2010) ise, üstel yumuşak geçiş fonksiyonunda yer alan konum parametresinin (location parameter) sıfıra eşit olduğuna ilişkin KSS'ce kabul edilen varsayımı hafifletilmiş ve Taylor yaklaştırma tekniğini kullanarak yumuşak geçişli modelin aşağıdaki yaklaşıklı̆̆ını elde etmiştir:

$$
\Delta y_{t}=\beta_{1} y_{t-1}^{3}+\beta_{2} y_{t-1}^{2}+\beta_{3} y_{t-1}+e_{t}
$$

Testin gücünü artırmak için Kruse (2010) 'ü sıfıra eşitlemekte ve eşitliğin sağ tarafina bağımlı değişkenin gecikmeli farklarını ilave ettiğinde $\tau$-istatistiğinin asimptotik dağılımının değişmediğini göstermektedir. Böylece 2 numaralı eşitlik aşağıdaki şekli almaktadır:

$\Delta y_{t}=\beta_{1} y_{t-1}^{3}+\beta_{2} y_{t-1}^{2}+\sum_{i=1}^{p} \rho_{i} \Delta y_{t-i}+e_{t}$

Burada durağanlığın belirlenmesi için şeklindeki birim kök sıfır hipotezi , doğrusal dışı durağanlığı ifade eden alternatife karşı test edilir. Bunun yapılması için Kruse (2010) Wald testinin değiştirilmiş bir versiyonu olan testini önerir.

Yapısal değişmenin anlık kırılma şeklinde değil de yumuşak geçiş şeklinde modellendiği LNV birim kök testi aşağıdaki üç lojistik regresyonla ifade edilir:

$$
\begin{aligned}
& y_{t=} \alpha_{1}+\alpha_{2} S_{t}(\gamma, \tau)+v_{t} \\
& y_{t=} \alpha_{1}+\beta_{1} t+\alpha_{2} S_{t}(\gamma, \tau)+v_{t} \\
& y_{t=} \alpha_{1}+\beta_{1} t+\alpha_{2} S_{t}(\gamma, \tau)+\beta_{2} t S_{t}(\gamma, \tau)+v_{t}
\end{aligned}
$$

Burada rejimler arası geçişi temsil eden lojistik yumuşak geçiş fonksiyonudur. Üç regresyonda doğrusal olmayan bileşenler sırasıyla trendden arındırılmamış serinin ortalamasında, trendden arındırılmış serinin ortalamasında ve trendden arındırılmıss serinin ortalaması ve eğiminde geçiş şeklinde modele dahil edilmiștir. Lojistik yumuşak geçiş fonksiyonları örnek hacmine $(T)$ dayanmakta olup şu şekilde ifade edilir. $S_{t}(\gamma, \tau)=[1+\exp \{-\gamma(t-\tau T)\}]^{-1}$. LNV birim kök testinin uygulanması iki aşamadan oluşmaktadır. İlk aşamada lojistik regresyonlar tahmin edilir. İkinci aşamada ise elde edilen hata terimlerine ADF testi uygulanır.

Sollis (2004) tarafından geliştirilen asimetrik intibakı da dikkate alan birim kök testi LNV regresyonlarının hata terimlerine dayanır ve aşağıdaki eşik otoregresiv modelle ifade edilir:

$\Delta v_{t}=I_{t} \rho_{1} v_{t-1}+\left(1-I_{t}\right) \rho_{2} v_{t-1}+\sum_{i=1}^{k} \phi_{i} \Delta v_{t-i}+\eta_{t}$

Burada eğer, eğer ve ortalaması sıfır olan durağan süreçtir. Sollis (2004) seride birim kök vardır şeklindeki sıfır hipotezini test etmek için için -istatistiğii ni ve/veya ve için değerlerinden istatistiksel olarak daha anlamlı olanını önermektedir.

Cuestas ve Ordóñez (2012) tarafından önerilen doğrusal olmayan birim kök testi de doğrusal dışılığın iki kaynağını dikkate almaktadır. Bunlar yapısal geçiş ve asimetrik uyumdur. Deterministik trendin yanı sıra asimetrik uyuma da izin veren Cuestas ve Ordóñez (2012) testi şu şekilde açıklanabilir:

$y_{t}=g(t)+\epsilon_{t}$

Burada $g(t)$ zamanın sabit olmayan bir fonksiyonudur ve şeklinde modellenir. ise şeklinde tanımlanan bir lojistik yumuşak geçiş fonksiyondur. Birim kök incelemesinin yapılması için Cuestas ve Ordóñez (2012) 8 numaralı eşitliğin hata terimleri serisine KSS testini uygulamayı önerirler.

\section{Veri Seti ve Bulgular}

Dünya Bankası Global Economic Monitor veri tabanından alınan Rusya RER'e ait veri seti 234 gözlemden oluşmakta olup Kasım 1993 - Nisan 2013 dönemini kapsamaktadır. Bu serinin zaman yolu Grafik 1'de verilmiştir. Grafikte 1995 yılının ortalarında RER'in önemli ölçüde arttığı görülmektedir. Bu artış aynı dönemde döviz kuru artışlarının kontrol altına alındığı fakat fiyat artışlarının bir süre daha yüksek oranda devam etmesinden kaynaklanır. 


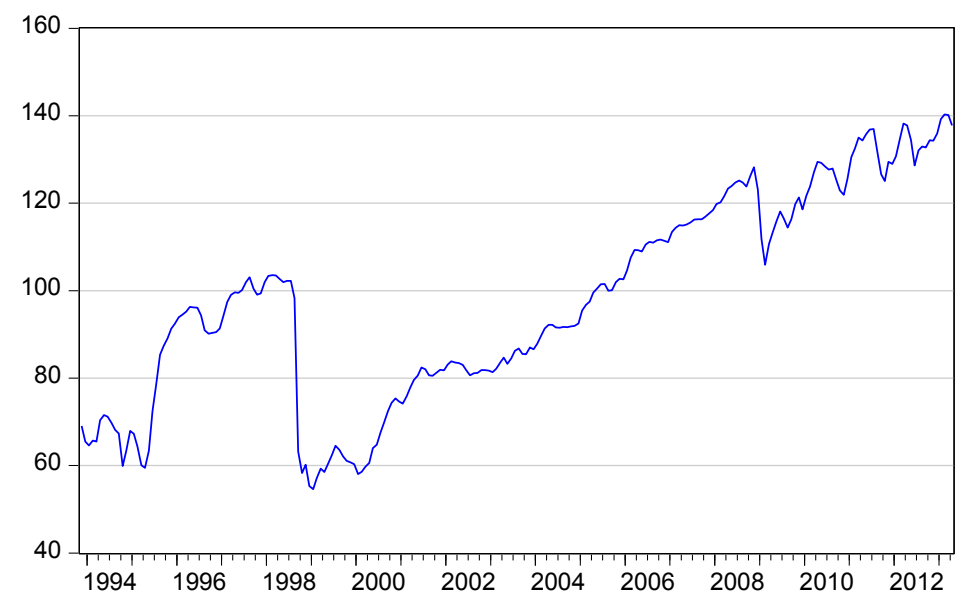

Şekil 1. RER Zaman Yolu

Seride ikinci bir kırılma 1998 yılında yaşanmıştır ki bu kırılma Rusya krizinin etkisini yansitır. 2000 sonrası yılarda ise ülke ihracatının artması ve enerji fiyatlarındaki artış RER'in Kasım 2008'e kadar artmasına neden olmuştur. 2008 yllı sonundaki düşüşten sonra RER daha istikrarsız bir seyir izlemesine karşın artış eğilimi devam etmiş̧ir.
ADF birim kök testi sonuçları Tablo 3'de sunulmuştur. Trende ilişkin farklı doğrusal varsayımlara sahip ADF testine ait bulgular RER'in durağan olmadığını gösterir. Yapisal değişmenin yumuşak geçiş şeklinde modellendiği KSS, Kruse (2010) ve LNV birim kök testlerinin sonuçları sırasıyla Tablo 4, 5 ve 6 'da verilmiştir. Doğrusal dışı intibakı da dikkate alan bu test

Tablo 3. ADF Birim Kök Testi Sonuçları

\begin{tabular}{|l|l|l|}
\hline Trend durağan & Sabit durağan & Sifır ortalama durağan \\
\hline$-2.6177(1)$ & $-1.3754(1)$ & $0.6912(1)$ \\
\hline
\end{tabular}

Not: Parantez içindeki sayılar minimum Schwarz bilgi kriterine (SCI) göre gecikme uzunluklarını gösterir.

Tablo 4. KSS Birim Kök Testi Sonuçları

\begin{tabular}{|c|c|c|}
\hline $\begin{array}{c}\text { Ortalama, trendden arındırılmış veri } \\
\text { için } t \text {-istatistikleri }\end{array}$ & $\begin{array}{c}\text { Ortalamadan arındırılmış veri için } t- \\
\text { istatistikleri }\end{array}$ & Ham veri için $t$-istatistikleri \\
\hline-1.8335 & -1.8780 & 0.2068 \\
$(-3.13)$ & $(-2.66)$ & $(-1.92)$ \\
\hline
\end{tabular}

Not: Parantez içindeki değerler \%10 anlamlılık düzeyi için kritik değerler olup KSS (2003)'e dayanmaktadır.

Tablo 5. Kruse (2011) Birim Kök Testi Sonuçları

\begin{tabular}{|c|c|c|}
\hline $\begin{array}{c}\text { Ortalama, trendden arındırılmış veri } \\
\text { için } t \text {-istatistikleri }\end{array}$ & $\begin{array}{c}\text { Ortalamadan arındırılmış veri için } t- \\
\text { istatistikleri }\end{array}$ & Ham veri için $t$-istatistikleri \\
\hline 3.499 & 4.9314 & 1.7608 \\
$(11.10)$ & $(8.60)$ & $(7.85)$ \\
\hline
\end{tabular}

Not: Parantez içindeki değerler \%10 anlamlılık düzeyi için kritik değerler olup Kruse (2011)’e dayanmaktadır.

Table 6. LNV Birim Kök Testi Sonuçları

\begin{tabular}{c|c|c|}
\hline Ortalamada ve eğimde yumuşak geçiş & Ortalamada yumuşak geçiş ve eğim & Ortalamada yumuşak geçiş \\
\hline-4.118737 & -3.617619 & -3.412525 \\
$(-4.572)$ & $(-4.337)$ & $(-3.851)$ \\
\hline
\end{tabular}

Not: Parantez içindeki değerler 200 gözleme ait \%10 anlamlılık düzeyi için kritik değerler olup LNV (1998)'e dayanmaktadır. 
sonuçları Rusya RER serisinin durağanlığını destekleyici herhangi bir bulgu sunmamaktadır.

Yapısal değișmenin yanı sıra asimetrik intibakı da dikkate alan Sollis (2004) ve Cuestas ve Ordóñez (2012) birim kök testi sonuçları Tablo 7 ve 8'de verilmiştir. Sollis (2004) testi ortalamada ve eğimde yu- muşak geçișe izin veren modeline ait -istatistiği \%5 düzeyinde istatistiksel olarak anlamlıdır. Aynı testin ortalamada yumuşak geçiş ve eğim eklenmiş modeline ait -istatistiği 200 gözlem için \%10 kritik değerine çok yakındır. Cuestas ve Ordóñez (2012) testi -istatistiği de $\% 5$ anlamlılık düzeyinde reel döviz kurunun asimetrik intibakını desteklemektedir.

Table 7. Sollis (2004) Birim Kök Testi Sonuçları

\begin{tabular}{c|c||c|c||c|c|}
\hline$t s_{\alpha}$ & $F_{\alpha}$ & $t s_{\alpha(\beta)}$ & $F_{\alpha(\beta)}$ & $t s_{\alpha \beta}$ & $F_{\alpha \beta}$ \\
\hline-2.578710 & 5.842547 & -3.512183 & 7.229108 & $-\mathbf{4 . 0 7 0 2 0 3 *}$ & 9.744464 \\
$(-3.140)$ & $(7.759)$ & $(-3.523)$ & $(10.232)$ & $(-3.704)$ & $(11.349)$ \\
\hline
\end{tabular}

Not: Parantez içindeki değerler 200 gözleme ait \%10 anlamlılık düzeyi için kritik değerler olup Silos (2004)'e dayanmaktadır. * simgesi ilgili istatistiğin $\% 5$ düzeyinde anlamlı olduğunu gösterir.

\begin{tabular}{l} 
Tablo 8. Cuestas ve Ordóñez (2012) Birim Kök \\
Testi Sonuçları \\
\hline$t$-istatistiği \\
\hline$-\mathbf{3 . 6 2 0 1 7 8}^{*}$ \\
\hline
\end{tabular}

Not: Cuestas ve Ordóñez (2012)'e göre 250 gözlem için \%1, 5 ve 10 anlamlllık düzeyi için kritik değerler sırasıyla $-3.928,-3.386$ ve -3.110 'dur. * simgesi ilgili istatistiğin $\% 5$ düzeyinde anlamlı olduğunu gösterir.

\section{Sonuç ve Değerlendirme}

$\mathrm{Bu}$ çalışmada PPP hipotezinin Rusya için geçerliliği RER serisinin durağanlık özellikleri asimetrik intibaka izin veren ve vermeyen doğrusal olmayan birim kök testleri çerçevesinde incelenerek araştırılmıştır. Çalışmada kullanılan doğrusal olmayan yaklaşımlara dan ilk üçü yapısal değişmeyi yumuşak geçiş şeklinde modelleyen KSS (2003), Kruse (2011) ve LNV (1998) testleridir. $\mathrm{Bu}$ testlerde rejim değişikliğinin geçişin orta noktasına göre simetrik olduğu varsayılmaktadır. Sollis (2004) ve Cuestas ve Ordóñez (2012) testleri ise bu varsayım kaldırılmakta ve yapısal değişmenin yanı sıra asimetrik intibaka da izin verilmektedir. Doğrusal ADF ile doğrusal dışılığı dikkate alan KSS, Kruse (2011) ve LNV birim kök testlerine ait test sonuçları ruble RER serisinin durağan olmadığını gösterir. Asimetrik intibaka izin veren Sollis (2004) ve Cuestas ve Ordóñez (2012) testlerine ait sonuçları ise ruble RER'in doğrusal dışı asimetrik uyumunu yani PPP hipotezinin Rusya için geçerliliğini desteklemektedir.

Elde edilen sonuçlar rublenin ABD doları reel kurunun kullanıldığı Telatar ve Hasanov (2009) ile RER'in kullanıldığı Nusair (2013) çalışmalarında Rusya’ya ilişkin elde edilen sonuçlarla benzedir. Rusya merkezi planlamaya dayalı ekonomik sistemin dağılmasından sonra piyasa ekonomisine geçmiş ve sistemin liberal- leşmesine yönelik bir dizi yapısal dönüşüm reformları gerçekleştirmiştir. Bunun yanı sıra 1998 yılında yaşanan Rusya krizi, 2000 sonrasi yıllarda enerji ihracatının artması ile dünya enerji fiyatlarının yükselmesi, 2008 krizinde sermaye kaçışı döviz kuru politikasında değişikliğe neden olmuştur. Piyasa ekonomisine yönelik yapısal dönüşüm reformlarının ve politika değişikliklerinin RER'de doğrusal dışı intibaka neden olduğu söylenebilir. Bu intibakın simetrik olması gerektiğine ilişkin ise bir gereklilik bulunmaktadır.

\section{Kaynakça}

Ağayev, S. (2013). Satın Alma Gücü Paritesi Hipotezinin Kazakistan İçin Geçerliliğii. Uluslararası Avrasya Ekonomileri Konferans1, 17-18 Eylül 2013, St. Petersburg, Rusya.

Baharumshah, A.Z. ve Borsic, D. (2008). Purchasing Power Parity in Central and Eastern European Countries. Economics Bulletin, 6(32), 1-8.

Bahmani-Oskooee, M., Kutan, A.M. ve Zhou, S. (2008). Do Real Exchange Rates Follow a Nonlinear Mean Reverting Process in Developing Countries? Southern Economic Journal, 74(4), 1049-1062.

Bahmani-Oskooee, M., Kutan, A.M. ve Zhou, S. (2009). Towards Solving The PPP Puzzle: Evidence From 113 Countries. Applied Economics, 41(24), 3057-3066.

CBR: The Central Bank of the Russian Federation Monetary Policy Measures http://cbr.ru/eng/ $\mathrm{dkp} /$ print.aspx?file=standart_system/policy_e. html\&pid=dkp\&sid=ITM_32899\#03 (Erişim: 12.05.2013) 
Chang, T., Lee, C.H. ve Hung, K. (2012). Can The PPP Sand On The BRICS? The ADL Test for Threshold Cointegration. Applied Economics Letters, 19(12), 1123-1127.

Chang, H.L., Liu, D.C. ve Su, C.W. (2012) Purchasing Power Parity with Flexible Fourier Stationary Test for Central and Eastern European Countries. Applied Economics, 44(32), 4249-4256.

Chang, T. ve Liu, W.C. (2010). Long-run Purchasing Power Parity with Asymmetric Adjustment: Evidence From Nine Major Oil-Exporting Countries. International Journal of Finance \& Economics, 15(3), 263-274.

Chang, H.L., Su, C.W., Zhu, M.N. ve Liu, P. (2010). Long-run Purchasing Power Parity and Asymmetric Adjustment in BRICs. Applied Economics Letters, 17(11), 1083-1087.

Chang, H.L., Su, C.W., Zhu, M.N. ve Liu, P. (2011). Reexamining Long-run Purchasing Power Parity for Central and Eastern European Countries: Nonlinear Panel Unit Root Tests. Applied Economics Letters, 18(5), 411-415.

Chang, T. ve Tzeng, H.W. (2011). Long-run Purchasing Power Parity with Asymmetric Adjustment: Further Evidence From Nine Transition Countries. Economic Modelling, 28(3), 1383-1391.

Choudhry, T. (1999). Purchasing Power Parity in HighInflation Eastern European Countries: Evidence From Fractional and Harris-Inder Cointegration Tests. Journal of Macroeconomics, 21(2), 293-308.

Cuestas, J.C. ve Ordóñez, J. (2012). Smooth Transitions, Asymmetric Adjustment and Unit Roots. Sheffield Economics Research Paper No. 2012012, Department of Economics, University of Sheffield.

Dickey, D.A. ve Fuller, W.A. (1979). Distribution of the Estimators for Autoregressive Time Series with a Unit Root. Journal of the American Statistical Association, 74(336a), 427-431.

EBRD, Transition Report, European Bank for Reconstruction and Development, London (1998-2008 saylları).

IMF, World Economic Outlook Database April 2013.

Kapetanios, G., Shin, Y. ve Snell, A. (2003). Testing for a Unit Root in the Nonlinear STAR Framework. Journal of Econometrics, 112(2), 359-379.
Kruse, R. (2011). A New Unit Root Test against ESTAR Based On a Class of Modified Statistics. Statistical Papers, 52(1), 71-85.

Leybourne, S., Newbold, P. ve Vougas, D. (1998). Unit Roots and Smooth Transitions. Journal of Time Series Analysis, 19(1), 83-97.

Liu, S., Zhang, D. ve Chang, D. (2012). Purchasing Power Parity - Nonlinear Threshold Unit Root Test for Transition Countries. Applied Economics Letters, 19(18), 1781-1785.

Lu, Y.C.R., Chang, T. ve Lee, C.H. (2012). Nonlinear AdE justment to Purchasing Power Parity in Transition Countries: The ADL Test for Threshold Cointegration. Applied Economics Letters, 19(7), 629-633.

Nusair, S.A. (2013). Real Exchange Rate Dynamics in Transition Economies: A Nonlinear Analysis. International Journal of Finance and Economics, 18(2), 188-204.

Sideris, D. (2006). Purchasing Power Parity in Economies in Transition: Evidence from Central and East European Countries. Applied Financial Economics, 16(1-2), 135-143.

Solakoglu, E.G. (2006). Testing Purchasing Power Parity Hypothesis for Transition Economies. Applied Financial Economics, 16(7), 561-568.

Sollis, R. (2004). Asymmetric Adjustment and Smooth Transitions: A Combination of Some Unit Root Tests. Journal of Time Series Analysis, 25(3), 409-417.

Su, C.W. ve Chang, H.L. (2011). Revisiting Purchasing Power Parity for Central and East European Countries Using Rank Tests for Nonlinear Cointegration. Eastern European Economics, 49(1), 5-12.

Su, C.W., Chang, H.L., Chang, T. ve Lee, C.H. (2012). Purchasing Power Parity for BRICS: Linear and Nonlinear Unit Root Tests with Stationary Covariates. Applied Economics Letters, 19(16), 1587-1591.

Telatar, E. ve Hasanov, M. (2009). Purchasing Power Parity in Transition Economies: Evidence from the Commonwealth of Independent States. PostCommunist Economies, 21(2), 157-173.

Yotopoulos, P.A. ve Sawada, Y. (2006). Exchange Rate Misalignment: A New Test of Long-run PPP Based on Cross-Country Data. Applied Financial Economics, 16(1-2), 127-134.

WB, World Bank Global Economic Monitor, 2013. 